\title{
Research on Special Effects Aesthetic Presentation and Reflection of Film Digital Technology \\ Xiao Han
}

\author{
Chongqing College of Electronic Engineering, University Town, Shapingba District, Chongqing, P. R. China
}

84865814@qq.com

Keywords: Film Digital Technology, Visual Design, Special Effects Production

\begin{abstract}
Film as an important part of the cultural industry, in the digital wave swept under the global scale is also undergoing a profound change in the traditional digital film is to accelerate the transformation of digital cinema. Digital film has become the inevitable trend of modern film technology. This paper establishes the research thought of the digital film as the research object and the visual picture design as the research core. This paper analyzes the difference between digital cinema and traditional film to reflect the advantage and development of digital cinema. Film is the perfect combination of technology and art products, film production is a rigorous implementation of the technology and rich artistic imagination of the depth of the complex process of integration. On the basis of the above, the paper analyzes the combination of illusory visual art and real art and the visual effect of digital cinema, in order to further clarify the digital film to bring people to enjoy the visual.
\end{abstract}

\section{Theoretical Introduction of Digital Film Technology}

Digital films refer to digital technology and equipment, production, storage of feature films and sports, arts and advertising, through satellite, optical fiber, disk, CD-ROM and other physical media transmission will meet the technical requirements of the digital signal reduction to video and sound , Showing the film and television works on the screen. Digital is changing the traditional sense of the film. The industry believes that the digital film is following the sound into the silent film, color instead of black and white, the film's third revolution. Digital technology will be incredible to expand the film's performance space and performance capabilities, creating people unheard of, never seen, or even want to think of the visual spectacle and virtual reality.

Digital technology to prepare for the preparatory work has brought great convenience. Including script writing, production budget and production of such works can be completed by the computer. The impact of digital technology on pre-preparation is more reflected in the visualization of pre-trial. In the film production process, the visualization pre-trial is in the shooting before, with the computer and the corresponding software, according to the creative staff and imagination, with analog images produced by analog clips. It can help the director, photographer and actor in the shooting beforehand can understand the general effect of the film in advance, and make the appropriate adjustments. Visualization pre-trial has been adopted by more and more film directors, not only can design a perfect visual effect, but also improve the shooting efficiency ${ }^{[1]}$.

The use of software on the real shot of the camera or software-generated screen processing, resulting in the film required special images and so on. Digital image synthesis is in the computer, the use of computer graphics and image principles, a variety of materials mixed together. Although this is similar to the traditional chemical printing method, but its function is much more powerful. Theoretically, the level of computer synthesis can be infinite. Computer generated images, also known as computer graphics and computer imaging technology. People use computer software from the establishment of the digital model until the video generated by the required dynamic picture, in the whole process can completely without the participation of the camera.

\section{Difference between Digital Film and Traditional Film}

The difference between digital cinema and film from the film production process, production 
methods, distribution and dissemination of the way are fully digital technologies. Compared with the traditional film, the biggest difference between digital film is no longer the film as the carrier to copy the way for the release, and for the digital file format issued or through the network, satellite directly to the theater, home and other end users. Digital broadcasting is a high-brightness, high-definition, high contrast electronic projector relying on broadband digital storage to achieve ${ }^{[2]}$. Fig.1 shows difference between digital film and traditional film.

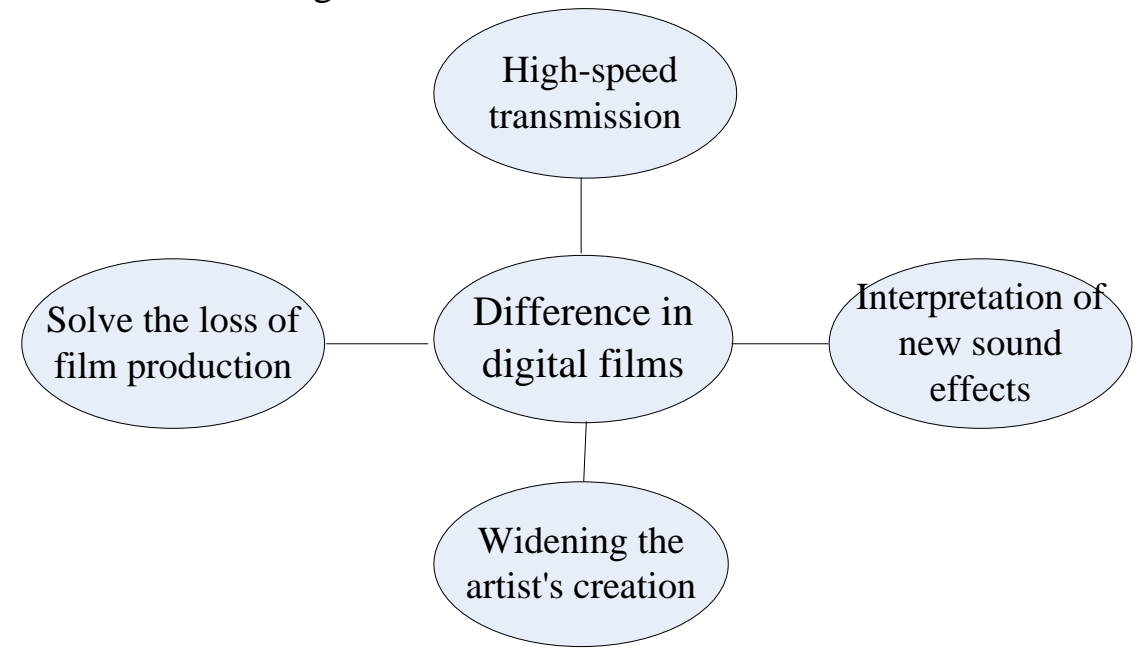

Fig.1. Difference between digital film and traditional film

Digital film technology into the microscopic world, it will image decomposition into the smallest unit pixel, and then re-combination to change or rebuild a part of the images and scenes, create a general photography method can't reach the gripping lens. 3D production process of each lens can be divided into: the production of physical model, the scan model to be sketches, computer modeling, restore texture, adding lights, effects and other rendering aspects of post-processing, and screen synthesis to achieve the final results. Digital film can interpret the new sound surround sound effects, greatly expanded the performance of film sound space, the film sound of the appeal, power of shock reached an unprecedented level; from the image effect, the color is more clear, full, clarity greatly improve. In addition, digital technology to create extreme virtual space and a variety of incredible scenes, these are ordinary film production methods can't be displayed.

Digital film to maximize the production and distribution process to solve the problem of loss of digital technology to avoid the traditional film from the original material to the copy to copy the film after several times over and over again screen, videotape scratches, even if repeated screenings But also does not affect the quality of audio and video. Digital film for the development of the film provides a new historical opportunity: the digital film is the film art to create a new world of wings; digital film for anti-piracy technology breakthrough we have a higher protection technology; digital film nonlinear editing time Software, auxiliary equipment, the output system and other technology leap will bring a new face of traditional film; and in the film, the development of game products, network products, are for the digitization of digital products, such as digital products, The artists of the film era provide a space for rapid development.

\section{Combined with Digital Technology and Art}

Digital technology from development to the present has been closely integrated with the film and the development of all digital technology applications are in order to achieve and achieve artistic results and painstaking research and development, with the improvement of people's material life, people's spiritual field Requirements are constantly changing, the new art forms of film performance methods are bold ahead of the step, such as all kinds of computer games and online games appear, are media art forms of upgrade change. The creation of these shapes also follows the art form of law and effective control of color, composition, visual rhythm, the overall effect. Through the people's imagination and virtual ideas to digital film performance of the field and manifestations began to diversify ${ }^{[3]}$. 
Internet-based digital film technology and the core of the Internet is gradually changing the way of life and appreciation of human beings, but also began to have an impact on the development of the film. The birth of the network film is not based on the original type of rich and development, but the birth of a new film style. Digital technology and film art is not contradictory, but rather more in line with the nature of the film. The film itself is a combination of art and technology products, the film in the history of every major technological change is bound to bring changes in the concept of film. Numerical technology becomes the material basis for the expression of film art, film creators to provide strong artistic creation Material protection. Although the digital technology as a carrier of the art of film appeared in the history of the development of the film, but the digital significance is not limited to this, it has more far-reaching potential for development, more traditional film carrier irreplaceable advantage. Digital technology to film creators of the imagination is infinitely expanded; the film reproduction of the true representation of a more realistic; the film has repeatedly expanded the meaning, and digital has exceeded the meaning of the film carrier.

So that the perfect combination of digital technology and film art, through the works of art to describe the relationship between image art and reality, with digital technology to complete the ultra-realistic sensory images, artistic perspective, Objective film world, people feel the immersive experience of film art to bring the viewer the same scenario, so that reality and creativity through each other, to guide people to a happy life a better yearning. Digital technology is the perception of the audience from the truth to ensure the authenticity of the film art, which is the theoretical basis of film image ontology. ${ }^{[4]}$.

\section{Special Effects Production of Digital Films}

In the latter part of the composition, you can use the special effects software to sort or modify the pre-shooting material, such as changing the color of the screen, the composition of the screen, the position of an element in the picture, etc., in order to pursue a special mood, the film in the postCommon synthesis methods. In order to achieve the harmonization of digital film color, control the relationship between the main color and complementary color in the picture is particularly critical. A specific color is always only one complementary color, to be a simple experiment to know. When we stare at a piece of red cloth with his eyes for a long time, and then quickly moved to the side of the white wall, the visual sense of the green wall full of green.

Keying technology is a digital film in the early stage of filming and post-synthesis of the most closely linked, keying technology using standard blue or green as the background, for specific people or objects, shooting scene material into the computer using special effects software for blue Green screen background separation. Usually blue screen used in television shooting more, the green screen used in the film more, the actual operation is not to define this, but according to the late need to use, using blue and green screen keying technology, will produce a very ambitious scene, In the works showing a different visual effects ${ }^{[5]}$. Fig.2 shows digital special visual effects.

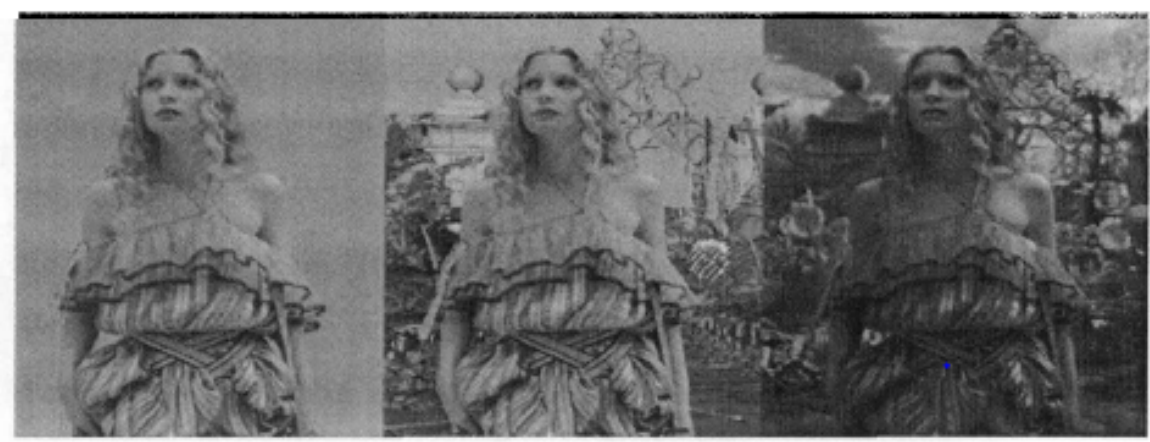

Fig.2. Digital special visual effects

Virtual shot in digital effect in bringing new technology to update and widely applied to visual effects. Virtual shooting should be made so that the director of the shooting action required, all in the virtual scene in the computer; shooting a variety of objects, including scenes, people, lights, all 
integrated into the computer. According to the director can finish their own intention, in the computer digital synthesis "command" role of performance and action, from any angle movement of his lens. In short, is to shoot the director to shoot any scene. However, all of the data entered into the computer is completely unmistakable from the real world. In other words, the virtual scene in the digital technology and virtual characters must be the real world and the actors of the "holographic" copy, is tantamount to a real world cloned to the computer in the fantasy world, so in the physical sense of "virtual" and "real" boundaries.

\section{Conclusions}

With the rapid development of computer technology, many traditional film productions can't be done with the computer lens, or the use of computer technology will make the film more beautiful. So the traditional film introduces digital technology. At present digital film technology is approaching maturity, the creative staff from the past simply the use of digital special effects and gradually transformed into traditional shooting, traditional stunt blend of expression techniques. In order to encourage thinking, innovation and practice through the current visual communication design. Any film-related technology innovation and the integration of new technology will have a significant impact on the films, and the most representative is the digital technology on the film late profound impact. Digital imaging performance is to convey a people-oriented to the film audience as the main spirit. Digital post-production, digital virtual effects, not only make the abandonment of the traditional film language, but also the film's language with more new expressions.

\section{References}

[1] Toby Miler, Nitin Govil, John M cmurria and Richard Maxwell. Hollywood, 2009.

[2] ZHANG Fan. Performing Art in the Digital Age [J] .Journal of Beijing Film Academy, 2010. (3): 85.

[3] Nie Zhong. Thoughts on Digitalization of Film [J]. Media Wide Angle .2011. (9): 24.

[4] Wang Ren and others. Film storm: digital art creation complete Raiders [M]. First edition. Beijing: Tsinghua University Press, 2009.

[5] ZHU Wei. Status and Development of Digital Film Industry in China [J]. Master's Degree Paper of Zhejiang University. 2011. 